\title{
Tetravalent Uranium Migration and Unrecoverable Uranium Resource Due to Fluorite
}

\author{
YANRU LIANG ${ }^{1}$, ZIRU PEI ${ }^{1}, \mathrm{CUI} \mathrm{LI}^{1}$, DAVID M. \\ PATERSON $^{2}$, PETER J. KOPITTKE ${ }^{3}$, WENMEI WU ${ }^{1}$ AND \\ PROF. YUHENG WANG, PHD ${ }^{1}$
}

${ }^{1}$ Northwestern Polytechnical University

${ }^{2}$ Australian Synchrotron

${ }^{3}$ The University of Queensland

Presenting Author: yuheng.wang.univ@gmail.com

The nuclear power industry generated 2657 TWh of electricity in 2019 , representing $\sim 10 \%$ of the world's total electricity production and $\sim 29 \%$ of low carbon power. The industry is mainly fueled by uranium, a radioactive and toxic element. Its enrichment in the environment can occur due to both geogenic processes, e.g., granite weathering, and anthropogenic activities, e.g., mining and milling. Uranium migration in the environment is controlled by its oxidation state, with hexavalent uranium [U(VI)] being highly soluble in aqueous phases whilst tetravalent uranium [U(IV)] is considered insoluble and immobile. Recent studies[1-6] show that noncrystalline U(IV) species are common in $U$ contaminated reducing environments, with these U(IV) species more susceptible to oxidation and mobilization than crystalline uraninite $\left(\mathrm{UO}_{2}\right)$. Therefore, the transformation of noncrystalline $\mathrm{U}(\mathrm{IV})$ into $\mathrm{UO}_{2}$ is considered favorable for $\mathrm{U}$ immobilization. Nevertheless, knowledge regarding the migration and fate of residual $U$ from mine and mill tailings, especially the role of common accessory minerals such as fluorite $\left(\mathrm{CaF}_{2}\right)$, is still scarce.

Here, we investigated the mechanisms by which $U$ is transported from a decommisioned granite-related mine to a downstream area. Uranium speciation throughout the successive transport bodies was characterized using electron microscopy, $\mathrm{X}$ ray fluorescence microscopy and microscale X-ray absorption spectroscopy. Surprisingly, we discovered evidence of mobile $\mathrm{U}^{\mathrm{IV}} \mathrm{O}_{2}-\mathrm{CaF}_{2}$ colloids in mine seepage and $\mathrm{U}^{\mathrm{IV} / \mathrm{VI}} \mathrm{O}_{\mathrm{x}}-\mathrm{CaF}_{2}$ aggregates in seepage sediment, with this demonstarting a role of $\mathrm{CaF}_{2}$ in facilitating $\mathrm{U}$ migration. These findings are important for two reasons. Firstly, the identification of these colloids demonstrates a remarkable but not-yet-reported mechanism of crystalline U(IV) transport in the environment. Secondly, the U in these colloids is encapsulated by $\mathrm{CaF}_{2}$ and is therefore not recoverable. As fluorite is widespread in various $U$ deposits[7], our discovery is of broad relevance to global recoverable $U$ resources and the nuclear power industry.

[1]Wang et al. (2013), Nat Commun 4, 2942

[2]Bargar et al. (2013), PNAS USA 110, 4506-4511

[3]Bhattacharyya et al., (2017), Nat Commun 8, 15538

[4]Noël et al. (2017), Environ Sci Technol 51, 10954-10964

[5]Seder-Colomina et al. (2018), Environ Sci Technol 52, 9515-9624

[6]Loreggian et al. (2020), Environ Sci Technol 54, 613-620

[7]IAEA, 1986, Vein type uranium deposits 